\title{
Conducting a COVID-19 Risk Assessment to Implement Evidence-based Decisions for Enabling Closure or Reopening of Schools
}

\author{
Saurabh Shrivastava, ${ }^{1}$ () Prateek Shrivastava² \\ 'Department of Community Medicine, Member of the Medical Education Unit and Institute \\ Research Council, Shri Sathya Sai Medical College \& Research Institute, Sri Balaji Vidyapeeth; \\ Deemed to be University, Ammapettai, Nellikuppam, Chengalpet District, Tamil Nadu, India \\ ${ }^{2}$ Department of Community Medicine, Shri Sathya Sai Medical College \& Research Institute, Sri \\ Balaji Vidyapeeth; Deemed to be University, Ammapettai, Nellikuppam, Chengalpet District, \\ Tamil Nadu, India
}

\section{ABSTRACT}

The Corona Virus Disease 2019 pandemic has compelled public health authorities to implement a wide range of public health and social measures to reduce the caseload and the spread of the novel viral infection. Owing to the implementation of various measures, some of the affected nations have demonstrated a decline in the incidence of the caseload, and it is the responsibility of the public health authorities to modify the implemented public health and social measures based on the epidemiological distribution and determinants. The decision should be based on the risk assessment which in itself is determined by the level of understanding about the disease transmission in children, local transmission pattern, and the readiness of the schools to reduce the possibility of emergence or appropriate management of an outbreak. In conclusion, as the epidemiological distribution of the disease is changing, it becomes vital for the public health authorities and school authorities to take specific steps on the closure or reopening of schools. However, regardless of any other factor, our interest should be to safeguard the well-being of staff and school children.

Keywords: COVID-19, schools, World Health Organization

\section{INTRODUCTION}

The Corona Virus Disease 2019 pandemic has compelled public health authorities to implement a wide range of public health and social measures to reduce the caseload and the spread of the novel viral infection. ${ }^{[1]}$ These measures included strategies to restrict the people's movement through closure of educational institutions, promoting work-from-home, avoiding social gatherings and encouraging people to stay indoors. ${ }^{[1]}$ Even then, the global estimates depict that 4088848 cases and 283153 deaths have been reported worldwide, with an overall case fatality gradually increasing to $6.9 \% .{ }^{[2]}$ At the same time, we should realize that the implementation of these restrictions has impacted both the social and economic domains of human lives. Thus, the nations should be on the look out to adopt these measures. ${ }^{[1,2]}$

\section{Relaxation of the Public Health and Social Measures in Schools}

Owing to the implementation of various measures, some of the affected nations have demonstrated a decline in the caseload incidence and it is the responsibility of the public health 
authorities to modify the implemented public health and social measures based on the epidemiological distribution and determinants. ${ }^{[3]}$ With regard to schools, it is important to take evidence-based decisions at the time of reopening or closing of schools after simultaneously considering the interests and safety of children, parents, teachers, and the society at large. ${ }^{[3,4]}$

\section{Risk Assessment}

This decision should be based on the risk assessment, which in itself is determined by the level of understanding about the disease transmission in children, local transmission pattern, and the readiness of the schools to reduce the possibility of emergence or appropriate management of an outbreak. The other indirect factors include assessment of the consequences of school closure on the rise in the incidence of domestic violence, limited access to meals, financial uncertainties, etc. ${ }^{[1,3,4]}$ At the same time, we should assess the capacity of the health sector to detect and respond to resurgence of cases and have a clear estimate about the children with special needs and staff who are vulnerable in schools due to underlying morbidities or due to their elderly age. ${ }^{[3]}$

\section{Implementation of Specific Measures by School Authorities}

The encouraging sign is that the available epidemiological and clinical evidence has demonstrated that the incidence of infection among children is less than adults and usually associated with the development of mild forms of disease among them. ${ }^{[3]}$ The school authorities should formulate specific strategies to ensure appropriate hand and respiratory hygiene, physical distancing and limit overcrowding by exploring the opportunity of reducing class size or alternate days of schools for children. ${ }^{[4,5]}$

It will be ideal to educate everyone about the behavioral modifications and develop a schedule to promote frequent hand washing and cleaning of the school environment. ${ }^{[4,5]}$ Moreover, specific decisions need to be taken to support distance teaching by vulnerable teachers, identifying the age-group of students that can be taught using tele-schooling and ways to maintain the students' safety in school through adequate supervision. The parents need to be informed that the sick child should not attend school, and the entire process can be streamlined by developing a checklist that can help both parents and staff to decide about attending school. ${ }^{[3,4]}$

The school authorities should explore the possibility of daily screening of body temperature and institute a mechanism for obtaining history about episodes of fever in the last 24 hours. ${ }^{[3]}$ Also, specific steps should be taken to maintain physical distancing by increasing desk spacing, limiting opportunities for mixing of classes and segregating sports activities, if at all planned. All options for teleschooling should be explored, and even if schools are reopened, the strict monitoring mechanism should be kept in place. ${ }^{[3]}$ These monitoring activities should assess the effects of various policies on educational objectives, learning outcomes and health and well-being of children and school staff. Moreover, all opportunities for collaboration between school and the local community should be encouraged, and the school authorities have a significant role to play. ${ }^{[1,3,4]}$

\section{CONCLUSION}

In conclusion, as the epidemiological distribution of the disease is changing, it becomes vital for the public health authorities and school authorities to take specific steps on the closure or reopening of schools. However, regardless of any other factor, our interest should be to safeguard the well-being of staff and school children.

\section{Disclosures}

Peer-review: Externally peer-reviewed.

Conflict of Interest: None declared.

Authorship Contributions: Concept - S.R.S.; Design - S.R.S., P.S.S.; Supervision - S.R.S., P.S.S.; Analysis and/or interpretation S.R.S., P.S.S.; Literature search - P.S.S.; Writing - S.R.S.; Critical review - S.R.S., P.S.S.

\section{REFERENCES}

1. Moberly T. Covid-19: school closures and bans on mass gatherings will need to be considered, says England's CMO. BMJ 2020;368:m806.

2. World Health Organization. Coronavirus disease 2019 (COVID-19) Situation Report - 113; 2020. Available at: https://www.who.int/docs/default-source/coronaviruse/situation-reports/20200512-covid-19-sitrep-113. pdf?sfvrsn=feac3b6d_2. Accessed Jun 30, 2020.

3. World Health Organization. Considerations for school-related public health measures in the context of COVID-19 - Annex to earlier guidance on adjusting public health and social measures. Geneva: WHO press; 2020. p: 1-5.

4. Viner RM, Russell SJ, Croker H, Packer J, Ward J, Stansfield C, et al. School closure and management practices during coronavirus outbreaks including COVID-19: A rapid systematic review. Lancet Child Adolesc Health 2020;4:397-404.

5. World Health Organization. 2019 Novel Coronavirus (2019-nCoV): Strategic preparedness and response plan. Geneva: WHO press; 2020. p: 1-20. 